\title{
Sensitivity and Specificity of Ankle Brachial Index (ABI) and Pulse Wave Handheld Doppler (PWHD) Compared with Angiography as Diagnostic Test for Patients with Peripheral Artery Disease (PAD)
}

Valdy Thomas ${ }^{1 *}$, Djony Tjandra ${ }^{2}$, Richard Sumangkut ${ }^{2}$, Billy Karundeng ${ }^{2}$, Grace Korompis ${ }^{3}$

Background: Peripheral artery disease (PAD) is a clinical condition that occurs due to atherosclerosis and narrowing of the arteries involving the aorta, branches of the visceral arteries such as the iliac arteries, and the arteries of the distal extremities. The femoropopliteal artery is the most commonly involved site in patients with atherosclerotic PAD. Ankle Brachial Index (ABI) determination may have limited value in some patients with diabetes, because calcification of the tibial artery can render it uncompressible, resulting in a very high $A B I$ value (>1.40). Handheld vascular Doppler with pulse volume waveform interpretation (PVW) is an easily available and non-invasive modality for evaluation of the inferior extremity arteries and can detect the severity of blood flow disturbances or ongoing PAD. The best diagnostic method for PAD is angiography using digital substraction angiography (DSA) to assess existing atherosclerotic lesions. The advantages of $A B I$ and PWHD examinations are in terms of simplicity, ease of use, and non-invasiveness instead of angiography in PAD diagnosis led the investigators to compare the sensitivity and specificity values between $A B I$ and PWHD with angiography as a diagnostic test for PAD patients.

Methods: This study used a cross-sectional diagnostic test design with the subjects were patients diagnosed with PAD, both outpatients and inpatients at Prof. DR. R.D Kandou Manado. ABI, PWHD and angiography examination were performed on all study subjects.

Results: The data show that $A B I$ has a sensitivity of $95.2 \%$ and a specificity of $80 \%$ in diagnosing PAD patients when compared to angiography as the standard of diagnosis of PAD. PWHD compared to angiography has a sensitivity of $100 \%$ and a specificity of $100 \%$. When $A B I$ and PWHD are combined, it has a sensitivity of $100 \%$ with a specificity of $80 \%$. The sensitivity and specificity of PWHD compared to angiography based on angiographic location in popliteal artery has a sensitivity of $91.7 \%$ and a specificity of $92.6 \%$. PWHD compared with angiography on posterior tibial artery (PTA) has a sensitivity of $81 \%$ and a specificity of $88.9 \%$. ABI compared with angiography on dorsalis pedis artery has a sensitivity of $100 \%$ and a specificity of $71.4 \%$, with $p<0.0001$.

Conclusion: The high sensitivity and specificity of $A B I$ and PWHD can be used as a diagnostic test tool for PAD patients by general practitioners in first level health facilities.

Keywords: diabetic foot, peripheral artery disease, angiography, Doppler, ankle brachial index

https://doi.org/10.36864/jinasvs.2021.1.005

${ }^{*}$ Correspondence: valdygiovano@gmail.com

${ }^{1}$ General Surgery Resident, Department of Surgery, Faculty of Medicine, University of Sam Ratulangi, Manado, Indonesia

${ }^{2}$ Department of Vascular Surgery, Faculty of Medicine, University of Sam Ratulangi, Manado, Indonesia

${ }^{3}$ Department of Public Health Sciences, Faculty of Medicine, University of Sam Ratulangi, Manado, Indonesia

\section{INTRODUCTION}

Peripheral arterial disease (PAD) is a clinical condition that results from atherosclerosis and narrowing of the arteries involving the aorta, branches of the visceral arteries such as the iliac arteries, and arteries of the distal extremities. The femoropopliteal artery is the most commonly involved site in patients with atherosclerotic PAD. ${ }^{1}$ The prevalence of PAD widely varies, ranging from $4 \%$ in
Copyright @ 2021, The Indonesian Society for Vascular and Endovascular Surgery

JINASVS 2021;2(1):10-16 
Table 1. Population Demographics

\begin{tabular}{lc} 
Characteristic & $\mathrm{n}=67(\%)$ \\
\hline Age (mean \pm SD) & $60.04 \pm 9.24$ \\
Gender (M:F) & $33: 34(49.2 \%: 50.8 \%)$ \\
ABI (mean \pm SD) & $0.79 \pm 0.16$ \\
Diabetes (\%) & $67(100)$ \\
CKD (\%) & $7(10.4)$ \\
Hypertension (\%) & $12(17.9)$ \\
CHF (\%) & $2(2.9)$ \\
Anemia (\%) & $7(10.4)$ \\
Hyperuricemia (\%) & $1(1.4)$ \\
AKI (\%) & $1(1.4)$ \\
Smoker (\%) & $1(1.4)$ \\
Stroke (\%) & $2(2.9)$ \\
Tuberculosis (\%) & $2(2.9)$ \\
\hline
\end{tabular}

(ABI:Ankle Brachial Index, CKD: Chronic Kidney Disease, CHF: Congestive Heart Failure, AKI:

Acute Kidney Injury, TB: Tuberculosis. SD:

Standard Deviation, M:F=Male:Female)

in Indonesia is $44 \%$, from the medical records data obtained from Harapan Kita Heart Center, the number of patients with lower limb PAD from January 2011 to February 2012 is 119 people. $^{6}$

Atherosclerotic processes, inflammation of the artery walls, vasospasm, thromboembolism, and fibromuscular dysplasia is thought to be the etiology of PAD. Ischemia or hypoxia, inflammation, and oxidative stress play a role in the pathophysiology of PAD. PAD is closely related to the risk of major cardiocerebrovascular events, thus the risk factors for PAD are similar to cardiocerebrovascular risk factors including family history, diabetes mellitus, smoking, chronic kidney disease, hypertension, obesity, lack of physical activity, and hyperlipidemia or dyslipidemia.
Tabel 2. ABI Measurement

\begin{tabular}{lcc}
\hline Result & $\mathrm{n}=67$ & $\%$ \\
\hline NORMAL & 4 & 6 \\
MILD & 46 & 68.7 \\
MODERATE & 16 & 23.9 \\
SEVERE & 1 & 1.5 \\
\hline Total & 67 & 100.0 \\
\hline
\end{tabular}

Smoking and diabetes mellitus are associated with a worse outcome and they are independent risk factors 7,8 The early detection targets for PAD is aimed for high-risk individuals aged > 65 years and individuals aged $>50$ years with a history of smoking or with diabetes mellitus. ${ }^{9,10,11}$

PAD causes an increased risk of major cardiocerebrovascular events and limb loss (amputation) in severe conditions thus early detection, correct diagnosis, and adequate treatment with supervised exercise, pharmacological therapy, revascularization therapy both with open surgery or endovascular intervention, and angiography is necessary to reduce the mortality and morbidity associated with PAD ensuring the better outcome. ${ }^{8,12}$

The ankle-brachial index (ABI) is a ratio of the systolic pressure of the lower limb (posterior tibial artery-PTA or dorsalis pedis artery) to the systolic blood pressure of the upper limb (brachial artery) measured in the supine position. This index can be measured using various measurement methods such as oscillometry, Doppler ultrasonography (duplex), plethismography, pulse measurement and auscultation, however the most widely used methods are oscillometry and Doppler methods. ${ }^{10,11}$ Physiological factors such as age, sex, height, race, measurement method, smoking habits, posture and body position can influence the results of the ABI measurements.

$A B I$ is an important examination method in diagnosing PAD. The normal ABI index ranges from

Table 3. PWHD Measurement

\begin{tabular}{|c|c|c|c|c|}
\hline \multirow[t]{2}{*}{ Location } & \multicolumn{3}{|c|}{ PWHD } & \multirow[b]{2}{*}{ Total } \\
\hline & Triphasic (\%) & Biphasic (\%) & Monophasic (\%) & \\
\hline Poplitea & $52(77.6)$ & $14(20.9)$ & $1(1.5)$ & $67(100)$ \\
\hline PTA & $18(26.9)$ & $31(46.3)$ & $18(26.9)$ & $67(100)$ \\
\hline Dorsalis Pedis & $5(7.5)$ & $35(52.2)$ & $27(40.3)$ & $67(100)$ \\
\hline
\end{tabular}

Table 4. Angiography Measurement

\begin{tabular}{lllllll}
\hline \multicolumn{1}{c}{ Location } & \multicolumn{7}{c}{ Angiography } \\
\hline & Grade 0 (\%) & Grade1 (\%) & Grade2 (\%) & Grade3 (\%) & Grade4 (\%) & Total \\
\hline Poplitea & $54(80.6)$ & $1(1.5)$ & $6(9.0)$ & $4(6.0)$ & $2(3.0)$ & $67(100)$ \\
PTA & $9(13)$ & $6(9)$ & $18(26.9)$ & $14(20.9)$ & $20(29.9)$ & $67(100)$ \\
Dorsalis Pedis & $7(10.4)$ & $0(0)$ & $17(25.4)$ & $9(13.4)$ & $34(50.7)$ & $67(100)$ \\
\hline
\end{tabular}

Table 5. Sensitivity and Specificity of ABI Compared to Angiography in Various Locations

\begin{tabular}{|c|c|c|c|c|c|c|c|}
\hline \multirow[b]{2}{*}{ LOCATION } & \multirow[b]{2}{*}{$A B I<0.9$} & \multicolumn{5}{|c|}{ ANGIOGRAPHY } & \\
\hline & & Grade 0 & Grade 1 & Grade 2 & Grade 3 & Grade 4 & \\
\hline \multirow{3}{*}{ POPLITEA } & Sensitivity & 92.6 & $100 \%$ & $100 \%$ & $100 \%$ & $100 \%$ & \\
\hline & Specificity & $7.40 \%$ & $7.40 \%$ & $7.40 \%$ & $7.40 \%$ & $7.40 \%$ & 0. \\
\hline & Sensitivity & $55.60 \%$ & $100 \%$ & $100 \%$ & $100 \%$ & $100 \%$ & \\
\hline PTA & Specificity & $44.40 \%$ & $44.40 \%$ & $44.40 \%$ & $44.40 \%$ & $44.40 \%$ & $0 . c$ \\
\hline \multirow{2}{*}{$\begin{array}{l}\text { DORSALIS } \\
\text { PEDIS }\end{array}$} & Sensitivity & $42.90 \%$ & $100 \%$ & $100 \%$ & $100 \%$ & $100 \%$ & \\
\hline & Specificity & $57.10 \%$ & $57.10 \%$ & $57.10 \%$ & $57.10 \%$ & $57.10 \%$ & $0 .($ \\
\hline
\end{tabular}


1.00 to 1.40 and $A B I<0.90$ or $>1.40$ is closely related to the incidence of PAD. Wang et al. found that there was an increased risk of occlusive disease with an increase in ABI. ${ }^{13}$ Several studies found sufficient sensitivity and specificity of ABI in diagnosing PAD. $A B I$ is superior to the other testing methods for PAD in terms of simplicity, easy to use, and non-invasive. However, ABI is not the gold standard for diagnosing PAD. ${ }^{2,14}$ ABI measurements may be limited in some patients with diabetes, because tibial artery calcification can makes it uncompressible, resulting in a very high ABI value $(>1.40) .{ }^{15}$ In a study by Faglia et al, ankle pressure could not be measured in 109 patients because there were occlusions on both tibial arteries ( 75 people) and the presence of calcifications in the arteries (34 people). ${ }^{9}$ In these circumstances another non-invasive vascular test should considered in making a diagnosis for PAD. ${ }^{16}$

Handheld vascular Doppler with pulse volume waveform (PVW) interpretation is widely available and non-invasive modality for the evaluation of the inferior extremity arteries and it can detect the severity of impaired blood flow or ongoing PAD. ${ }^{17} \mathrm{~A}$ study by Lewis et al. comparing ABI and PVW with Vascular Doppler ultrasonography (USG) found that ABI sensitivity is $\pm 79 \%$ with a specificity of $91 \%$ and an overall accuracy of $\pm 88 \%$; a PVW sensitivity of around $97 \%$ with a specificity of $81 \%$ and an overall accuracy of about $85 \%$; the combination of $A B I$ and PVW yields a sensitivity of $100 \%$ with a specificity of $76 \%$ and an overall accuracy of $85 \%$; Thus, the study concluded that these two modalities were sufficiently accurate methods to diagnose PAD. ${ }^{18}$

Evaluation of PAD from vascular Doppler ultrasound examination can be the basis for diagnosis, choice of treatment, and evaluation of the given therapy. Vascular Doppler ultrasound examination can provide information on the severity of the stenosis by interpreting the waves of blood flow in the arteries. In clinical practice, handheld Doppler has shown a high level of reliability. ${ }^{17}$ In performing audio analysis, non-pathological Doppler waveforms are considered to be multifacial, which includes biphasic (two) or triphasic (three) sounds. In contrast, a monophasic waveform is a single sound that is considered pathological. ${ }^{17}$ The loss of a triphasic waveform on Doppler examination can lead to occlusive disease. ${ }^{19}$

The best diagnostic method for PAD is angiography using digital substraction angiography (DSA) to assess the atherosclerotic lesions. ${ }^{20}$ DSA is a minimal invasive procedure with a high risk of bleeding, vascular damage, and embolization, so it is only used for cases where non-invasive imaging such as CT-Angiography or Magnetic Resonance Angiography (MRA) is inadequate. Conventional angiography is indicated in symptomatic PAD patients who are considered for revascularization. In the angiographic approach for diagnosing $P A D$, an assessment of three segments of the lower leg arteries, such as the aortoiliac, femoropopliteal, and arteries below the knee should be done; so that all peripheral arteries would be examined for the presence of anatomical variants, aneurysms, inflow and outflow disorders, and assess the proper blood vessels for revascularization as the angiosome concept. Angiography as a gold standard for diagnosing is also a therapeutic method where endovascular revascularization can be performed using either a stent or a balloon so that arterial occlusion can be relieved in cases of PAD. 9,21,22

The simplicity, easy to use, and non-invasive method of $A B I$ and PWHD examinations in assisting the diagnosis of PAD and angiography with digital subtraction angiography (DSA) as a standard diagnostic and therapeutic endovascular interventions for PAD motivate researchers to compare the sensitivity and specificity values between $A B I$ and PWHD with angiography as a diagnostic test for PAD patients.

\section{METHOD}

This is a cross-sectional diagnostic test study. The subjects were outpatients and inpatients of Prof. DR. R.D Kandou Manado General Hospital diagnosed with PAD. ABI, PWHD and angiography examination were performed on all study subjects. The research was conducted from March 2020 to October 2020. The study was conducted at the Department of General Surgery, Prof. DR. R.D. Kandou Manado General Hospital. The population in this study were all patients with PAD who were treated at this hospital with a total of 67 people. The research samples were PAD patients aged $\geq 18$ years who were able and willing to sign the informed consents. The sample would be filtered based on the inclusion and exclusion criteria. The inclusion criteria included the $A B I$ index can be measured, the patient never had peripheral artery revascularization previously, and the patient can be in supine position during examination. The exclusion criteria included patients who have one

Table 6. Sensitivity and Specificity of PWHD Compared to Angiography in Various Locations

\begin{tabular}{|c|c|c|c|c|c|c|c|}
\hline \multirow[b]{2}{*}{ LOCATION } & \multirow{2}{*}{$\begin{array}{c}\text { PWHD }+ \\
\text { (Bifasic, Monophasic) }\end{array}$} & \multicolumn{5}{|c|}{ ANGIOGRAPHY } & \multirow[b]{2}{*}{$\mathrm{p}$} \\
\hline & & Grade 0 & Grade 1 & Grade 2 & Grade 3 & Grade 4 & \\
\hline \multirow{3}{*}{ POPLITEA } & Sensitivity & $7.40 \%$ & $100 \%$ & $67 \%$ & $100 \%$ & $100 \%$ & \\
\hline & Specificity & $92.60 \%$ & $92.60 \%$ & $92.60 \%$ & $92.60 \%$ & $92.60 \%$ & 0.0001 \\
\hline & Sensitivity & $11.10 \%$ & $67 \%$ & $72 \%$ & $100 \%$ & $85 \%$ & \\
\hline PTA & Specificity & $88.90 \%$ & $88.90 \%$ & $88.90 \%$ & $88.90 \%$ & $88.90 \%$ & 0.0001 \\
\hline \multirow{2}{*}{$\begin{array}{l}\text { DORSALIS } \\
\text { PEDIS }\end{array}$} & Sensitivity & $28.60 \%$ & $100 \%$ & $100 \%$ & $100 \%$ & $100 \%$ & \\
\hline & Specificity & $71.40 \%$ & $71.40 \%$ & $71.40 \%$ & $71.40 \%$ & $71.40 \%$ & 0.0001 \\
\hline
\end{tabular}

Table 7. Sensitivity and Specificity Combined ABI and PWHD compared with Angiography ABI PWHD (+)

$<0,9 \quad$ Biphasic and Monophasic

\section{Combined}

ABI $<0,9$ and PWHD $(+)$ Biphasic and Monophasic

\begin{tabular}{lccc} 
Sensitivity (\%) & 95,2 & 100 & 100 \\
Specificity (\%) & 80 & 100 & 80 \\
\hline
\end{tabular}


or more of the following conditions; lymphedema, thrombophlebitis, cellulitis, and deep vein thrombosis (DVT). The other exclusion criteria were cancer patient, the patient had never a major amputation of the lower limb, the patient cannot supine, and the patient withdrawn from the study. The sample characteristics (such as: age and sex), comorbidities and $A B I$ categories were calculated for the frequency of distribution. The results of PWHD measurements and angiography are also categorized based on gradation and location. For the initial sensitivity and specificity measurement, the PWHD measurement which results as triphasic are classified as PWHD (-), the biphasic and monophasic PWHD results are classified as PWHD (+). All ABI categories (mild, moderate and severe) are grouped as ABI $(+)$ and the normal $A B I$ are grouped as ABI (-). For the gold standard, which is angiography; grade 1-4 angiography results are grouped as angiography $(+)$ and others results as angiography $(-)$. Analysis to obtain sensitivity and specificity values were cross tabulated with a significance level of $5 \%$, using statistical analysis program PAPP 1.4.1 (GNU software). Then the test was continued by comparing the sensitivity and specificity of each gradation and location. Ethical approval was obtained from each research samples and the Ethics Commission of Prof. R. D. Kandou Manado General Hospital.

\section{RESULTS}

The participant demographics are presented in Table 1 . Of the 67 participants who completed a full set of study measurements, the mean age was $60.05 \pm 9.24$ SD years, the samples in this study were 33 men and 34 women. Mean ABI was $0.79 \pm 0.16 \mathrm{SD}$. The main risk factor is type 2 diabetes mellitus in 67 people $(100 \%)$. Then hypertension 12 people $(17.9 \%)$, CKD 7 people $(10.4 \%)$, anemia 7 people $(10.4 \%)$, congestive heart failure, stroke and pulmonary tuberculosis are comorbidities suffered by the sample is 2 people each $(2.9 \%)$. The result of measurements ABI, PWHD and angiography at popliteal artery, posterior tibial artery (PTA), and dorsalis pedis artery are presented in Table 2, 3, 4. The result of sensitivity and specificity are presented in Table 5,6,7. In Table 7

is explained that ABI compared to angiography has a sensitivity of $95.2 \%$ and a specificity of $80 \%$. PWHD compared to angiography has $100 \%$ sensitivity and $100 \%$ specificity. When ABI and PWHD are combined, they will have a sensitivity of $100 \%$ with a specificity of $80 \%$.

Factors affecting venoplasty failure to maintain optimal $\mathrm{Qb}$ values were analyzed through logistic regression modeling (Table 2 ). Regardless of other factors (univariable model), the location of stenosis and the presence of DM comorbidities are 2 main factors that have the potential to increase the chance of venoplasty failure. After controlling for one of these variables (multivariable model), it was seen that cases with juxta anastomosis stenosis had a 14 times greater chance of venoplasty failure $(p=$ 0.037 ) than stenosis in draining veins or central veins. The presence of DM increased the odds of failure of venoplasty 12 times greater $(p=0.038)$ than when cases did not have this comorbid. The location of AVF had no effect on venoplasty results $(p=0.570)$.

\section{DISCUSSION}

The data shows that $A B I$ has a sensitivity of $95.2 \%$ and a specificity of $80 \%$ in diagnosing PAD patients when compared to the gold standard which is angiography. Various studies have reported that ABI had a sensitivity of $>90 \%$ and a specificity of more than $95 \%$ in diagnosing stenosis in the lower leg arteries when compared to angiography. ${ }^{55,56}$ Lijmer et al. reported that an $A B I$ value of $<0.91$ had a sensitivity of $79 \%$ and a specificity of $96 \%$ when compared to angiography in detecting PAD. ${ }^{57}$ Stoffers et al. also reported that an ABI value of $<0.97$ had a sensitivity of $79 \%$ and a specificity of $82 \% .{ }^{58}$

In this study we looked at the sensitivity and specificity of $A B I$ in diagnosing $P A D$ by finding the location of lesions in the lower limbs via angiography (Table 5,6$)$. ABI compared with angiography on A. popliteal had a sensitivity of $100 \%$ and a specificity of $7.4 \%$. ABI compared to angiography in A. PTA had a sensitivity of $100 \%$ and a specificity of $44.4 \%$. ABI compared with angiography on dorsalis pedis artery had a sensitivity of $100 \%$ and a specificity of $57.1 \%$, with $p<0.0001$. Thus, the researchers concluded that ABI has a high sensitivity $(100 \%)$ in detecting a stenosis with rate of $>30 \%$ on angiography. Dachun $\mathrm{Xu}$ et al. reported that in detecting a stenosis with rate of $\geq 50 \%$, ABI $<0.9$ varies in sensitivity $(15-79 \%)$ and specificity (83.3-99\%) (Table 1). ${ }^{59}$ The level of specificity tends to vary and low because the $A B I$ measurement is done on the dorsalis pedis artery or the posterior tibial artery, so the ABI measurement does not specifically detect stenosis in these two arteries, but it can also detect stenosis in a more proximal artery. ${ }^{59}$

The results showed that PWHD has a sensitivity of $100 \%$ and a specificity of $100 \%$ in diagnosing PAD. A study by Ro et al. evaluated the sensitivity of $A B I$, specificity of $A B I$ and subjective pulse volume waveform (PVW) analysis obtained from photoplethysmography (PPG), with subjective Doppler Waveform (DW) analysis compared to the gold standard computed tomography angiography (CTA). The test results of a total of 97 patients (194 feet) had a sensitivity and specificity of PPG-PVW analysis compared to CTA of $82 \%$ and $77 \%$, respectively; for DW analysis, a sensitivity of $91 \%$ and specificity of $65 \%$, and $A B I$ sensitivity of $70 \%$ and specificity of $97 \% .{ }^{60}$ Another study of Tehan et al. examined the sensitivity and specificity of continuous waveform doppler (CWD) compared to Dupplex ultrasound and angiography in detecting PAD with a stenosis rate of $50 \%$; CWD has a sensitivity of $81.75 \%$ when compared to Dupplex Ultrasound and has a sensitivity of $81 \%$ when compared to angiography. ${ }^{61}$

The results of our study found that the sensitivity varies depending on the location and degree of stenosis. Lowest PWHD sensitivity in detecting stenosis is in grade 1 (stenosis $<30 \%$ ) popliteal artery and grade 2 (30-60\% stenosis) PTA. It is because there are recognized physiological limitations associated with subjective PWHD analysis. First, PVW is dependent on peripheral blood flow and therefore can be affected by factors other than vascular patency such as sympathetic nerve input. Second, severe congestive heart failure can also slow down the blood flow and mimic inflow disease. Third, PVW represents the total blood flow of the area that is being assessed and therefore cannot provide 
accurate diagnostic information about the extent of particular injured artery. ${ }^{18}$

The results showed that the combination of ABI and PWHD compared to angiography in detecting PAD had a sensitivity of $100 \%$ and a specificity of $80 \%$. Lewis et al. used automatic measurement of $A B I$ and PVW to detect PAD compared to DW, ABI had a sensitivity of $79 \%$ and a specificity of $91 \%$, PVW had a sensitivity of $97 \%$ and a specificity of $81 \%$, and when the two were combined, they had a sensitivity of $100 \%$ and a specificity of $76 \%$. So, the researchers concluded that the combination of ABI and PWHD is an efficient, non-invasive, and easy diagnostic tool in diagnosing PAD.

The advantage of this study is to compare $A B I$ with PWHD as the initial screening for PAD patients. The PWHD device is cheap and easy to obtain, so it can be used by frontline medical personnel in diagnosing PAD patients. Another advantage of this study, it compares the sensitivity and specificity values of various locations and degrees of stenosis.

This research limitation is that the sensitivity and specificity of the test in this study did not include other variables in the analysis.

\section{CONCLUSION}

Ankle Brachial Index (ABI) and Pulse Wave Handheld Doppler (PWHD) have good sensitivity and specificity in detecting PAD. The combination of these two diagnostic modalities is an efficient, noninvasive, and an easy diagnostic test in diagnosing PAD. ABI and PWHD can be used by the frontline and rural medical personnel to diagnose PAD patients. We suggest a study on the sensitivity and specificity of combined $A B I$ and PWHD which included other variables.

\section{CONFLICT OF INTEREST}

The author states the original work, and there is no conflict of interest in doing this research.

\section{ORCID ID OF AUTHORS}

\section{REFERENCES}

1. Katsanos, K., Tepe, G., Tsetis, D., Fanelli, F. Standards of Practice for Superficial Femoral and Popliteal Artery Angioplasty and Stenting. Cardiovasc Intervent Radiol 2014;37:592-603

2. Nead, KT., Cooke, JP., Olin, JW., Leeper, NJ. Alternative Ankle-Brachial Index Method Identifies Additional At-Risk Individuals. J Am Coll Cardiol 2013;62:553-9

3. Fowkes, FG., Aboyans, V., Fowkes, FJ., McDermott, MM., Sampson, UK., Criqui, MH. Peripheral Artery Disease: Epidemiology and Global Perspectives. Macmillan Publishers 2016

4. Sampson, U., Fowkes, F., McDermott, M., et al. Global and Regional Burden of Death and Disability from Peripheral Artery Disease: 21 World Regions 1990-2010. Glob Heart 2014;9:145-58.e21

5. Purnayoga, B. Hubungan antara Indeks Massa Tubuh dengan Penyakit Arteri Perifer di Posyandu Lansia Nusa Indah Desa Pabelan Kartasura. Universitas Muhammadiyah Surakarta 2018

6. Elfi, EF. Peran Latihan Disupervisi pada Pasien dengan Penyakit Arteri Perifer Ekstremitas Bawah. MKA $2014 ; 37(2)$

7. Joosten, MM., Pai, JK., Bertoia, ML., et al. Associations between Conventional Cardiovascular Risk Factors and Risk of Peripheral Artery Disease in Men. JAMA 2012;308:1660-7

8. Olin, JW., White, CJ., Armstrong, EJ., Kadian-Dodov, D., Hiatt, WR. Peripheral Artery Disease: Evolving Role of Exercise, Medical Therapy, and Endovascular Options. Journal of the American College of Cardiology 2016;67(11)

9. Kullo, IJ., Rooke, TW. Peripheral Artery Disease. N Engl J Med 2016;374:861-71

10. Albu, MR., Iliuta, L., Guberna, SM., Sinescu, C. The Role of Ankle-Brachial Index for Predicting Peripheral Arterial Disease. Medica A Journal of Clinical Medicine 2014;9(3):295-302

11. Span, M., Gersak, G., Millasseau, SS., Meza, M., Kosir, A. Detection of Peripheral Arterial Disease with an Improved Automated Device: Comparison of a New Oscillometric Device and the Standard Doppler Method. Vascular Health and Risk Management 2016;12:305-311

12. Morcos, R., Louka, B., Tseng, A., Misra, S., McBane, R., Esser, H., et al. The Evolving Treatment of Peripheral Arterial Disease through Guideline-directed Recommendations. J Clin Med 2018;7:9

13. Wang, JC., Criqui, MH., Denenberg, JO., McDermott, MM., Colomb, BA., Fronek, A. Exertional Leg Pain in Patients with and without Peripheral Arterial Disease. Circulation 2005;112:3501-8

14. Sadeghi, M., Heidari, R., Mostanfar, B., Tavassoli, A., Roghani, F., Yazdekhasti, S. The Relation between Ankle-Brachial Index (ABI) and Coronary Artery Disease Severity and Risk Factors: An Angiographic Study. Arya Atherosclerosis $2011 ; 7(2): 68-73$

15. Marso Steven P, Hiatt William R. Peripheral arterial disease in patients with diabetes. J Am Coll Cardiol. 2006 Feb 2;47(5):921-29

16. Alavi A, Sibbald RG, Mayer D, et al. Pathophysiology and prevention: Diabetic foot ulcers Part I. J Am Acad Dermatol. 2014 Feb 10;70(1):19-20

17. Tehan Ellen $P$, Chuter Helaine V. Use of hand-held Doppler ultrasound examination by podiatrists:a reliability study. J Foot Ankle Res. 2015 Aug 12;36(8):2

18. Lewis, JAE., Williams, P., Davies, JH. Non-invasive Assessment of Peripheral Arterial Disease: Automated Ankle Brachial Index Measurement and Pulse Volume Analysis Compared to Duplex Scan. SAGE Open Medicine 2016;4:1-9

19. Gerassimidis T, Karkos CD, Karamanos $D$, et al. Current endovascular management of the ischaemic diabetic foot.International Working Group On The Diabetic Foot, The Netherlands. 2008 Des 2;12(2):6773 
20. Yokoi, Y. Basics of Angiography for Peripheral Artery Disease. InTech Open 2017

21. Chin, AS., Rubin, GD. CT Angiography of Peripheral Arterial Occlusive Disease. Tech Vasc Interventional Rad 2006;9:143-149

22. Said, ZH., Lerakis, S. The Role of Magnetic Resonance Angiography in Peripheral Artery Disease. Current Opinions in Pharmacology 2018;39:129-133

23. Pande, RL., Perlstein, TS., Beckman, JA., et al. Secondary Prevention and Mortality in Peripheral Artery Disease: National Health and Nutrition Examination Study 1999 to 2004. Circulation 2011;124:17-23

24. Hirsch, AT., Criqui, MH., Treat-Jacobson, D., et al. Peripheral Arterial Disease Detection, Awareness, and Treatment in Primary Care. JAMA 2001;286:1317-24

25. Nehler, MR., Duval, S., Diao, L., et al. Epidemiology of Peripheral Arterial Disease and Critical Limb Ischemia in An Insured National Population. J Vasc Surg 2014;60:686-95.e2

26. Hernando, FJ., Conejero, AM. Peripheral Artery Disease: Pathophysiology, Diagnosis, and Treatment. Rev Esp Cardiol 2007;60(9):969-82

27. Krishna, SM., Moxon, JV., Golledge, J. A Review of the Pathophysiology and Potential Biomarkers for Peripheral Artery Disease. Int J Mol Sci 2015;16:11294-11322

28. Hoyer, C., Sandermann, J., Petersen, LJ. The Toe-Brachial Index in the Diagnosis of Peripheral Arterial Disease. J Vasc Surg 2013;58:231-8

29. Aboyans, V., Criqui, MH., Abraham, P., et al., for the American Heart Association Council on Peripheral Vascular Disease, Council on Epidemiology and Prevention, Council on Clinical Cardiology, Council on Cardiovascular Nursing, Council on Cardiovascular Radiology and Intervention, and Council on Cardiovascular Surgery and Anesthesia. Measurement and Interpretation of the Ankle-Brachial Index: A Scientific Statement from the American Heart Association. Circulation 2012;126:2890-909

30. Lee, JY., Lee, SW., Lee, WS., et al. Prevalence and Clinical Implications of Newly Revealed Asymptomatic Abnormal Ankle-Brachial Index in Patients with Significant Coronary Artery Disease. J Am Coll Cardiol Intv 2013;6:1303-13

31. Lin, HW., Lee, IT. Combination of the Ankle-Brachial Index and Percentage of Mean Arterial Pressure to Improve Diagnostic Sensitivity for Peripheral Artery Disease: An Observational Study. Medicine 2018;97:39

32. Gerhard-Herman, MD., Gornik, HL., Barrett, C., Barshes, NR., Corriere, MA., Drachman, DE., et al. 2016 AHA/ACC Guideline on the Management of Patients with Lower Extremity Peripheral Artery Disease: Executive Summary. Circulation 2017;135:e686-725

33. McCarthy, CP., Shrestha, S., Ibrahim, N., Kimmenade, RR., Gaggin, HK., Mukai, R., et al. Performance of a Clinical/Proteomic Panel to Predict Obstructive Peripheral Artery Disease in Patients with and without Diabetes Mellitus. Open Heart 2019;6:e000955

34. Cooke, JP., Wilson, AM. Biomarkers of Peripheral Arterial Disease. J Am Coll Cardiol 2010;55:2017-23

35. McDermott, MM., Liu, K., Green, D., et al. Changes in D-dimer and Inflammatory Biomarkers before Ischemic Events in Patients with Peripheral Artery Disease: The BRAVO Study. Vasc Med 2016;21:1220

36. Rhee, SY., Kim, YS. Peripheral Arterial Disease in Patients with Type 2 Diabetes Mellitus. Diabetes Metab J 2015;39:283-290

37. American College of Cardiology Foundation., American Heart Association. ACCF/AHA Pocket Guideline: Management of Patients with Peripheral Artery Disease (Lower Extremity, Renal, Mesenteric, and Abdominal Aortic). ACC/AHA 2011

38. McDermott, MM., Domanchuk, K., Liu, K., et al. The Group Oriented Arterial Leg Study (GOALS) to Improve Walking Performance in Patients with Peripheral Arterial Disease. Contemp Clin Trials 2012;33:1311-20

39. McDermott, MM., Liu, K., Guralnik, JM., et al. Home-based Walking Exercise Intervention in Peripheral Artery Disease: A Randomized Control Trial. JAMA 2013;310:57-65

40. McDermott, MM., Guralnik, JM., Criqui, MH., et al. Home-based Exercise in Peripheral Artery Disease: 12-Month Follow-up of the GOALS Randomized Trial. J Am Heart Assoc 2014;3:e000711

41. Murphy, TP., Cutlip, DE., Regensteiner, JG., et al., for the CLEVER Study Investigators. Supervised Exercise versus Primary Stenting for Claudication Resulting from Aortoiliac Peripheral Artery Disease: Six-Month Outcomes from the Claudication: Exercise versus Endoluminal Revascularization Study. Circulation 2012;125:130-9

42. Murphy, TP., Cutlip, DE., Regensteiner, JG., et al. Supervised Exercise, Stent Revascularization, or Medical Therapy for Claudication due to Aortoiliac Peripheral Artery Disease: the CLEVER Study. J Am Coll Cardiol 2015;65:999-1009

43. Aboyans, V., Ricco, JB., Bartelink, ML., Bjorck, M., Brodmann, M., Cohnert, T., et al. 2017 ESC Guidelines on the Diagnosis and Treatment of Peripheral Arterial Diseases in Collaboration with the European Society for Vascular Surgery (ESVS). European Heart Journal 2018;39:763-821

44. Sabedotti, M., Sarmento-Leite, R., Quadros, AS. Ankle-Brachial Index as a Predictor of Significant Coronary Artery Disease in Patients Undergoing Coronary Angiography. Rev Bras Cardiol Invasiva 2014;22(4):359-63

45. Allison, MA., Hiatt, WR., Hirsh, AT., Coll, JR., Criqui, MH. A High Ankle-Brachial Index is Associated with Increased Cardiovascular Disease Morbidity and Lower Quality of Life. J Am Coll Cardiol 2008;51:12928

46. Aboyans, V., Lacroix, P., Tran, MH., Salamagne, C., Galinat, S., Archambeaud, F., et al. The Prognosis of Diabetic Patients with High Ankle-Brachial Index Depends on the Coexistence of Occlusive Peripheral Artery Disease. J Vasc Surg 2011;53:984-91

47. Mahé Guillaume, Boulon Carine, Desormais Ileana et al. Statement for doppler waveforms analysis. J. Vascular Diseases. May 2017 22:1-9 p 
48. Limpeleh L, Sumangkut RM, Tjandra DE. Korelasi Antara Gambaran Spektral Doppler Arteri Tibialis Posterior dan Arteri Dorsalis Pedis dengan Skor Pedis pada Penderita Ulkus Kaki Diabetikdi RSUP Prof. Dr. R. D. Kandou. J Biomedik. 2018 July;10(2):97-105 p

49. Sibley $R$, Reis $S$, Reddick $M$, et al. Noninvasive Phsiologic vascular studies: a guide to diagnosing peripheral arterial disease. J Radiological Society of North America. 2016 Sep 30;37(1):1-12

50. Creutzig A, Vesti AB, Minar E et al. VASA. European J of Vascular Medicine. 2017;46(5):339 p

51. Staneva Milena. Vascular Ultrasound as Diagnostic Modalities for PAD. BEC.2014:7 p

52. Sidawy NA. Rutherford's Vascular Surgery and Endovascular Theraphy. Diabethic Neuropathy. $9^{\text {th }}$ rev. ed. Perler AB, translator.Philadelphia; 2019,1515-34 p.

53. Soulez, G., Therasse, E., Giroux, MF., Bouchard, L., Gilbert, P., Perreault, P., et al. Management of Peripheral Arterial Disease: Role of Computed Tomography Angiography and Magnetic Resonance Angiography. Presse Med 2011;40:e437-452

54. Loewe, C., Schoder, Maria., Rand, Thomas., Hoffman, Udo., Sailer, Johannes., Kos, Thomas., Lammer, Johannes., Thurnher, Siegfried. Peripheral Vascular Occlusive Disease: Evaluation with contrastEnhanced Moving-Bed MR Angiography Versus Digital Subtraction Angiography in 106 Patients. AJR 2002;179:1013-1021p

55. Hirsch AT, Haskal ZJ, Hertzer NR, et al. ACC/AHA 2005 Guidelines for the Management of Patients With Peripheral Arterial Disease (Lower Extremity, Renal, Mesenteric, and Abdominal Aortic): A Collaborative Report from the American Association for Vascular Surgery/Society for Vascular Surgery, Society for Cardiovascular Angiography and Interventions, Society for Vascular Medicine and Biology, Society of Interventional Radiology, and the ACC/AHA Task Force on Practice Guidelines (Writing Committee to Develop Guidelines for the Management of Patients With Peripheral Arterial Disease) J Am Coll Car. 2006;47:e1-192.

56. McDermott MM, Liu K, Criqui MH, et al. Ankle-brachial index and subclinical cardiac and carotid disease. The multi-ethnic study of atherosclerosis. Am J Epidemiol. 2005;162:33-41.

57. Lijmer JG, Hunink MG, van den Dungen JJ, Loonstra J, Smit AJ. ROC analysis of noninvasive tests for peripheral arterial disease. Ultrasound Med Bio. 1996;22:391-98.

58. Stoffers $\mathrm{HE}$, Kester AD, Kaiser V, Rinkens PE, Knottnerus JA. The diagnostic value of the measurement of the ankle- brachial sys tolic pressure index in primary health care. J Clin Epidemiol. 1996;49:140105.

59. Dachun Xu, Jue Li, Liling Zou, Yawei Xu, Dayi Hu, Pagoto SL, Yunsheng Ma. Sensitivity and specificity of the ankle-brachial index to diagnose peripheral artery disease: a structured review..Vasc Med. 2010 Oct;15(5):361-9. doi: 10.1177/1358863X10378376.

60. Ro DH, Moon HJ, Kim JH, et al. Photoplethysmography and continuous-wave Doppler ultrasound as a complementary test to ankle-brachial index in detection of stenotic peripheral arterial disease. Angiology 2013; 64: 314-320.

61. Tehan, PE, Sebastian, M, Barwick, AL. How sensitive and specific is continuous-wave Doppler for detecting peripheral arterial disease in people with and without diabetes? A cross-sectional study. Diab Vasc Dis Res 2018; 15: 396-401 